\title{
Post-traumatic thrombotic microangiopathy following pelvic fracture treated with transcatheter arterial embolization: a case report
}

Kaori Ikegami ${ }^{{ }^{*}}$, Takuma Yamagishi ${ }^{1}$, Junya Tajima ${ }^{2}$, Yukinori Inoue ${ }^{1}$, Ken Kumagai ${ }^{1}$, Yasuo Hirose ${ }^{1}$, Daisuke Kondo ${ }^{1}$ and Koji Nikkuni ${ }^{1}$

\begin{abstract}
Background: Thrombotic microangiopathy is caused by various conditions, but few cases secondary to trauma have been reported. We present the rare case of a patient with thrombotic microangiopathy-induced high-impact trauma with hemorrhagic shock.

Case presentation: An 86-year-old Japanese woman was transferred to our hospital after a traffic accident. A whole-body computed tomography scan revealed pelvic fractures with massive extravasation. She received a blood transfusion and emergency angiographic embolization. On post-traumatic day 1, she showed unexplained severe hemolysis, thrombocytopenia, and renal failure despite her stable condition. Disseminated intravascular coagulation was excluded because her activated partial thromboplastin time and prothrombin time-international normalized ratio were normal. Her fragmented red blood cell concentration was $28.8 \%$. We suspected clinical thrombotic thrombocytopenic purpura and started plasma exchange. She recovered fully after the plasma exchange and was discharged on day 31. We eventually diagnosed thrombotic microangiopathy because her ADAMTS13 activity was not reduced.

Conclusions: It is important to recognize the possibility that thrombotic microangiopathy may occur after severe trauma. In the critical care setting, unexplained thrombocytopenia and hemolytic anemia should be investigated to eliminate the possibility of thrombotic microangiopathy. Early plasma exchange may help to prevent unfortunate outcomes in patients with thrombotic microangiopathy following trauma.
\end{abstract}

Keywords: TMA, Hemolysis, Thrombocytopenia, ADAMTS13, Trauma

\section{Background}

Thrombotic thrombocytopenic purpura (TTP) is a life-threatening condition and medical emergency. It is characterized by a pentad of thrombocytopenia, microangiopathic hemolytic anemia, central neurological disorders, renal failure, and fever. The ADAMTS13 (also known as von Willebrand factor-cleaving protease) activity or ADAMTS antibody level is now used in the diagnosis of

\footnotetext{
* Correspondence: hosp-kaori-ike@hosp.niigata.niigata.jp

${ }^{1}$ The Department of Emergency and Critical Care Medicine, Niigata City General Hospital, 463-7 Shumoku, Chuo-ku, Niigata, Niigata 950-1197, Japan Full list of author information is available at the end of the article
}

TTP. Plasma exchange is essential in the treatment of TTP.

Postoperative TTP has been frequently described, whereas post-traumatic TTP is extremely rare. Here we report a case of post-traumatic thrombotic microangiopathy (TMA) that was successfully treated with plasma exchange.

\section{Case presentation}

An 86-year-old multiparous Japanese woman with an unremarkable medical history was transferred to our hospital after a traffic accident (Table 1). She was hit by a car while walking at a crosswalk. On presentation to our emergency department, she complained of pain in her buttock. Her

(c) The Author(s). 2018 Open Access This article is distributed under the terms of the Creative Commons Attribution 4.0 International License (http://creativecommons.org/licenses/by/4.0/), which permits unrestricted use, distribution, and 
Table 1 Laboratory findings on admission

\begin{tabular}{|c|c|c|}
\hline \multicolumn{3}{|l|}{ Serum chemistry } \\
\hline $\mathrm{Na}$ & 141 & $\mathrm{mmol} / \mathrm{l}$ \\
\hline K & 4.1 & $\mathrm{mmol} / \mathrm{l}$ \\
\hline $\mathrm{Cl}$ & 102 & $\mathrm{mmol} / \mathrm{l}$ \\
\hline $\mathrm{Ca}$ & 9.5 & $\mathrm{mg} / \mathrm{dl}$ \\
\hline Total protein & 6.6 & $\mathrm{~g} / \mathrm{dl}$ \\
\hline Albumin & 3.3 & $\mathrm{~g} / \mathrm{dl}$ \\
\hline Blood urea nitrogen & 17.8 & $\mathrm{mg} / \mathrm{dl}$ \\
\hline Creatinine & 0.89 & $\mathrm{mg} / \mathrm{dl}$ \\
\hline Total bilirubin & 0.7 & $\mathrm{mg} / \mathrm{dl}$ \\
\hline AST & 43 & $\mathrm{IU} / \mathrm{I}$ \\
\hline ALT & 31 & $\mid \mathrm{IU} / \mathrm{I}$ \\
\hline $\mathrm{LDH}$ & 449 & $\mathrm{IU} / \mathrm{I}$ \\
\hline CK & 217 & $\mathrm{IU} / \mathrm{I}$ \\
\hline \multicolumn{3}{|l|}{ Blood cell count } \\
\hline WBC & $11.1 \times 10^{9}$ & $/ 1$ \\
\hline $\mathrm{RBC}$ & $3.25 \times 10^{12}$ & $/ 1$ \\
\hline $\mathrm{Ht}$ & 30.2 & $\%$ \\
\hline $\mathrm{Hb}$ & 10.6 & $\mathrm{~g} / \mathrm{dl}$ \\
\hline Platelets & $193 \times 10^{9}$ & $/ 1$ \\
\hline RBC fragmentation & 0 & \\
\hline \multicolumn{3}{|l|}{ Coagulation tests } \\
\hline PT-INR & 1.1 & \\
\hline aPTT & 35.1 & seconds \\
\hline FDP & 1073 & $\mu \mathrm{g} / \mathrm{dl}$ \\
\hline
\end{tabular}

Glasgow Coma Scale score was 15/15. Her blood pressure was 100/53 $\mathrm{mmHg}$, heart rate was 93 beats/minute, respiratory rate was 15 breaths/minute, and oxygen saturation was $100 \%$ while breathing $2 \mathrm{~L} /$ minute of oxygen. A whole-body computed tomography scan revealed fractures of her left pubic bone and sacrum and a hematoma with contrast extravasation in front of the sacrum (Fig. 1). Her blood pressure then suddenly dropped to $67 / 38 \mathrm{mmHg}$ secondary to hemorrhagic shock. Rapid resuscitation with fluids and blood was performed. We attempted to perform transcatheter arterial embolization (TAE). Based on angiographic findings (Fig. 2), bilateral internal iliac artery embolization was performed with gelatin sponge particles. She received $560 \mathrm{ml}$ of packed red cells, $480 \mathrm{ml}$ of fresh frozen plasma, and $200 \mathrm{ml}$ of platelets, and she became hemodynamically stable.

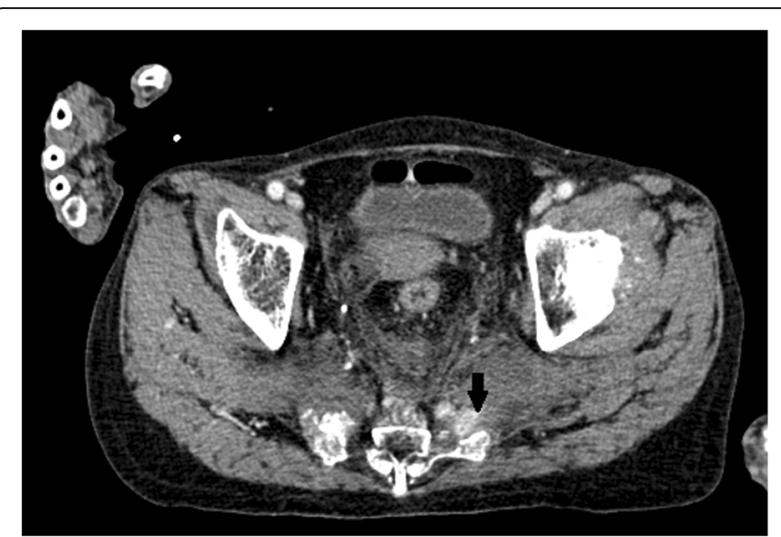

Fig. 1 Contrast-enhanced computed tomography of the patient with pelvic fractures after trauma. The arrow indicates a hematoma with extravasation

After admission to our intensive care unit, she developed shaking chills and a high fever. She was hemodynamically stable the following day. However, reddish urine was observed. Her serum lactate dehydrogenase level was extremely high, and fragmented red blood cells were present on peripheral blood smears. On the third day of hospitalization, despite fluid challenges and the use of diuretics, she became anuric and thus underwent hemodialysis. However, she developed severe delirium and was intubated under sedation. She was not diagnosed as having TTP at this point because her platelet count was not reduced despite the worsening of her

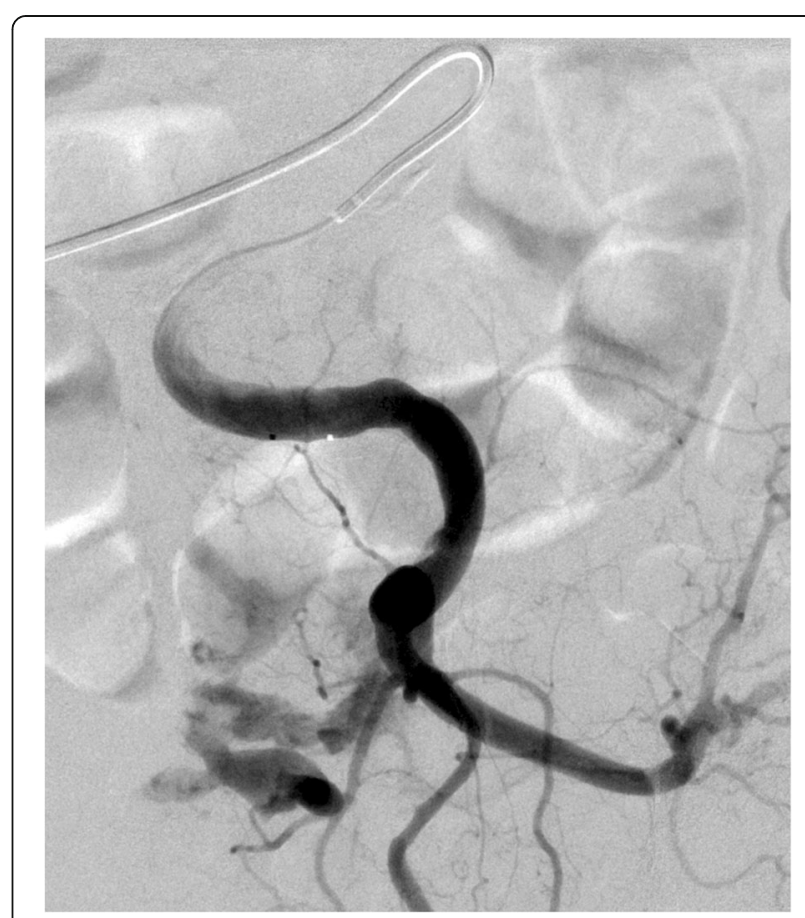

Fig. 2 Catheterization of the left internal iliac artery with massive extravasation indicating active bleeding 
hemolysis. Her prothrombin time and activated partial thromboplastin time were normal, and her fibrin degradation products were returning toward the normal concentration within 3 days of admission; therefore, disseminated intravascular coagulation (DIC) was excluded.

On the fifth day of hospitalization, her platelet count, measured by a different hemocytometer, was very low. Her fragmented red blood cell concentration measured by visual judgment based on the International Council for Standardization in Haematology (ICSH) reference method was $28.8 \%$ (Fig. 3). We finally confirmed the diagnosis of TTP based on the classic pentad of TTP and began plasma exchange.

After retrospectively checking her platelet count, we found that it had decreased to $55 \times 10^{9} / \mathrm{L}$ on the second day of hospitalization (Fig. 4). The presence of many fragmented red cells is often associated with a spurious increase in the platelet count because the fragmented red cells are erroneously measured as platelets by automated blood cell counters.

Plasma exchange was continued for 5 consecutive days. Her clinical course dramatically improved in just a few days, and her platelet count increased. She was weaned from hemodialysis on the 15th day of hospitalization. She recovered fully and was discharged from our hospital on the 31st day of hospitalization. The ADAMTS13 activity measured by an enzyme immunoassay on the third hospital day was not reduced (65\%), but a direct Coombs test was negative and the complement factor level was normal.

\section{Discussion}

TMA, which includes TTP/hemolytic-uremic syndrome, is now a commonly used term. TMA is a pathological condition characterized by thrombocytopenia, microangiopathic hemolytic anemia, and organ injury. Primary TMA

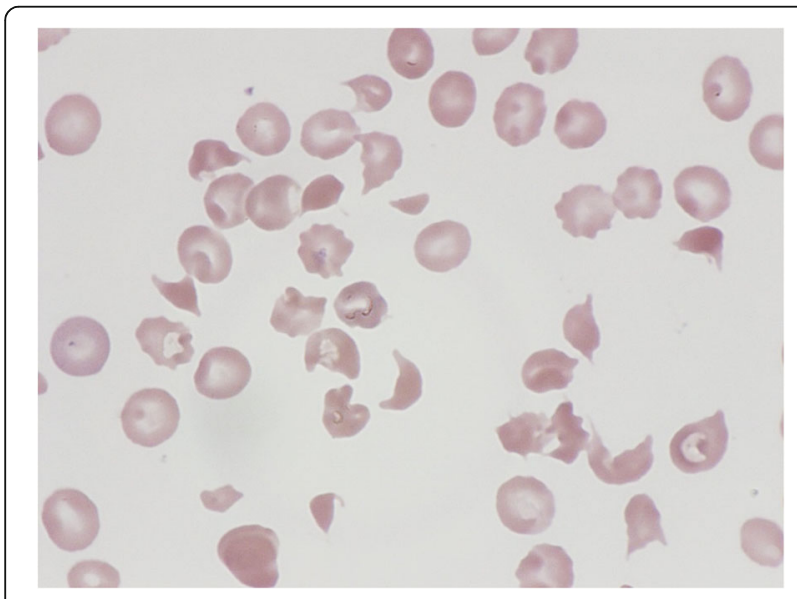

Fig. 3 Peripheral blood smear shows multiple fragmented red cells. The platelet count is reduced includes hereditary or acquired TTP, Shiga toxin-mediated hemolytic-uremic syndrome, complement-mediated TMA, drug-induced TMA, coagulation-mediated TMA, and metabolism-mediated TMA [1]. TTP was first reported by Moschcowitz in 1924 [2]. The onset of TTP appears to have a close association with ADAMTS13. TTP is typically defined as an ADAMTS13 activity of $<10 \%$ [3].

Secondary TTP may result from various conditions including connective tissue disease, transplantation, malignancy, pregnancy, and drugs $[4,5]$. Surgery-induced TTP has also been reported in several cases [6], and it most commonly occurs after cardiac and vascular surgery [7]. The previously reported cases of secondary TTP did not necessarily rely on the detection of ADAMTS13 activity for the diagnosis. The mechanism of secondary TTP is less clear. In our patient, the ADAMTS13 activity was not significantly reduced, although she had the classic pentad of TTP. Post-traumatic TTP/TMA is quite rare. To the best of our knowledge, only one case report of TTP/TMA secondary to trauma has been reported in the English language literature [8]; this report was by Lim and Park [8], who described a case of TTP after blunt traumatic liver injury.

When thrombocytopenia occurs in association with trauma, we consider extravascular loss, consumption, dilution, DIC, and heparin-induced thrombocytopenia as differential diagnoses. Although DIC meets the pathological definition of TMA, here we describe DIC and TMA separately. The differential diagnosis of DIC and TMA is clinically difficult, but it is very important because the optimal therapy differs between the two conditions. Our patient rapidly developed thrombocytopenia and severe hemolysis despite normal coagulation test results, which was inconsistent with DIC. She did not have progressive anemia, and the hematoma did not increase in size on follow-up computed tomography. There was no possibility of hemolytic transfusion reaction, and we reaffirmed no problems based on the results of a cross-matching test. The development of hemolysis after intravascular treatment has been reported in cases involving closure of a patent duct arteriosus [9] and in association with infectious complications of Clostridium perfringens [10]. Our patient had severe vascular injury despite the presence of minor fractures; in addition, she received TAE. Whether the TMA was associated with the TAE in our case is unclear, but it is a possibility. Severe pelvic injury and embolization induce the endothelial cells of small vessels to produce high levels of unusually large von Willebrand factor multimers, which are higher than the level that can be processed by ADAMTS13.

Our patient's clinical course dramatically improved due to plasma exchange in spite of the fact that administration of fresh frozen plasma was ineffective. This result may suggest that the effect of removing excess unusually large von Willebrand factor multimers, among several 


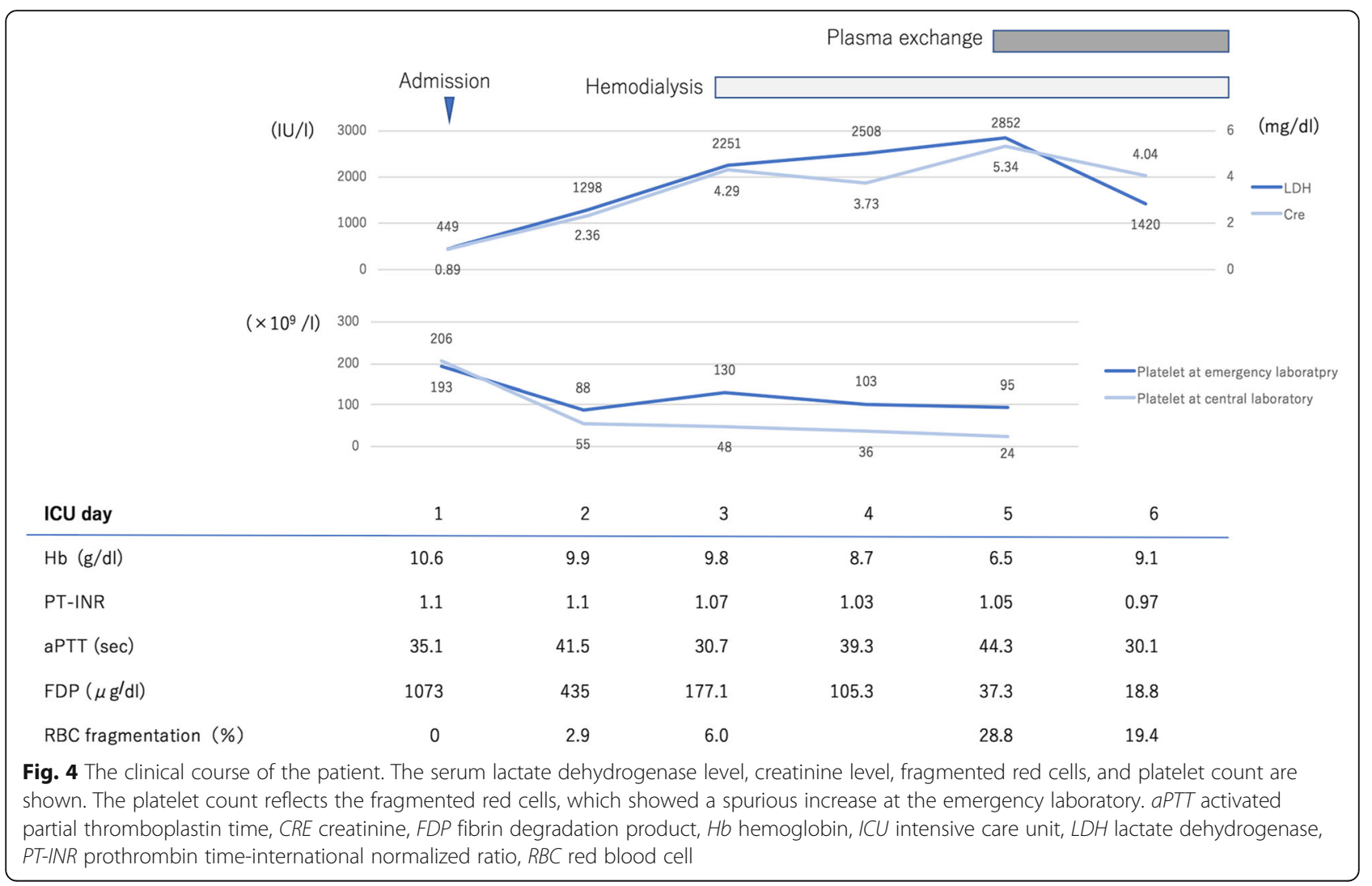

other effects of plasma exchange, contributed greatly to her outcome. Established guidelines advocate that treatment with plasma exchange should be initiated as soon as possible [11] if TTP is suspected. Plasma exchange might be the only possible life-saving therapy in patients with TMA following trauma.

In our hospital, the hematology analyzer (Celltac F; Nihon Kohden Corporation, Tokyo, Japan) at the emergency laboratory revealed little difference in the platelets versus the fragmented red cells, whereas that at the central laboratory (ADVIA 2120i; Siemens Healthineers, Erlangen, Germany) precisely analyzed them. The automated blood counter at the central laboratory used two-dimensional analysis through the addition of hemoglobin measurement, not just the size of the blood cells, allowing discrimination of platelets from fragmented red cells. When the platelet count is not consistent with severe hemolysis, we should reevaluate the thrombocytopenia with a different technique or visual counting method.

In conclusion, TMA must be considered in the differential diagnosis of unexplained thrombocytopenia and hemolytic anemia in patients with trauma. Plasma exchange must be performed without delay if TMA is suspected. Further progress in the clarification of TMA is expected in the future.

\section{Conclusions}

It is important to recognize the possibility that TMA may occur after severe trauma. In the critical care setting, unexplained thrombocytopenia and hemolytic anemia should be investigated to eliminate the possibility of TMA.

\section{Abbreviations}

DIC: Disseminated intravascular coagulation; TAE: Transcatheter arterial embolization; TMA: Thrombotic microangiopathy; TTP: Thrombotic thrombocytopenic purpura

\section{Availability of data and materials \\ Please contact author for data requests.}

\section{Authors' contributions}

$\mathrm{Kl}, \mathrm{TY}, \mathrm{JT}, \mathrm{YI}$, and $\mathrm{KK}$ provided intensive medical care as a team. YH carried out transcatheter arterial embolization. KN helped us by giving advice as a hematology specialist. DK carried out plasma exchange. YH helped to draft the manuscript. All authors read and approved the final manuscript.

\section{Ethics approval and consent to participate}

This case report has been approved by the research ethics committee of our hospital.

\section{Consent for publication}

Written informed consent was obtained from the patient for publication of this case report and any accompanying images. A copy of the written consent is available for review by the Editor-in-Chief of this journal.

\section{Competing interests}

The authors declare that they have no competing interests. 


\section{Publisher's Note}

Springer Nature remains neutral with regard to jurisdictional claims in published maps and institutional affiliations.

\section{Author details}

${ }^{1}$ The Department of Emergency and Critical Care Medicine, Niigata City General Hospital, 463-7 Shumoku, Chuo-ku, Niigata, Niigata 950-1197, Japan. ${ }^{2}$ The Department of Intensive Care Medicine, Yokohama City Minato Red Cross Hospital, 3-12-1 Shin-yamashita Naka-Ku, Yokohama, Kanagawa 231-8682, Japan

Received: 22 July 2017 Accepted: 28 June 2018

Published online: 09 August 2018

\section{References}

1. George JN, Nester CM. Syndromes of thrombotic microangiopathy. N Engl J Med. 2014:371(7):654-66

2. Moschcowitz E. Hyaline thrombosis of the terminal arterioles and capillaries: a hitherto undescribed disease. Proc N Y Pathol Soc. 1924;24:21-4.

3. Bianchi V, Robles R, Alberio L, Furlan M, Lämmle B. Von Willebrand factor-cleaving protease in thrombocytopenic disorder: A severe deficit activity is specific for thrombotic thrombocytopenic purpura. Blood. 2002:100(2):710-3.

4. Dahlan R, Sontrop JM, Li L, Ghadieh O, Clark WF, et al. Primary and secondary thrombotic microangiopathy referred to a single plasma exchange center for suspected thrombotic thrombocytopenic purpura: 2000-2011. Am J Nephrol. 2015:41(6):429-37.

5. Fujimura Y, Matsumoto M. Registry of 919 patients with thrombotic microangiopathies across Japan: Database of Nara Medical University during 1998-2008. Intern Med. 2010;49(1):7-15.

6. Eskazan AE, Buyuktas D, Soysal T. Postoperative thrombotic thrombocytopenic purpura. Surg Today. 2015;45(1):8-16.

7. Choi EJ, Lee S. A postoperative thrombotic thrombocytopenic purpura in a cardiac surgery patient: A case report. Korean I Thorac Cardiovasc Surg. 2013;46(3):220-2.

8. Lim KH, Park J. Thrombotic thrombocytopenic purpura after blunt traumatic liver injury. Am J Emerg Med. 2016;34(5):939. e3-4

9. Tomita H, Fuse S, Akagi T, Matsumoto Y, Murakami Y, Shiraya H, et al. Hemolysis complicating coil occlusion of patent ductus arteriosus. Catheter Cardiovasc Diagn. 1998;43(1):50-3.

10. Oshima S, Takaishi K, Tani N, Hirano M, Ikeda K, Makari Y, et al. Two cases of liver abscess caused by Clostridium perfringens after transcatheter arterial chemoembolization. Gan To Kagaku Ryoho. 2013;40(12):1795-7.

11. Scully M, Hunt BJ, Benjamin S, Liesner R, Rose P, Peyvandi F, et al. Guidelines on the diagnosis and management of thrombotic thrombocytopenic purpura and other thrombotic microangiopathies. Br J Haematol. 2012;158(3):323-35.

Ready to submit your research? Choose BMC and benefit from:

- fast, convenient online submission

- thorough peer review by experienced researchers in your field

- rapid publication on acceptance

- support for research data, including large and complex data types

- gold Open Access which fosters wider collaboration and increased citations

- maximum visibility for your research: over $100 \mathrm{M}$ website views per year

At BMC, research is always in progress.

Learn more biomedcentral.com/submissions 